\title{
Effects of Withania somnifera Nicotine Induced Conditioned Place Preference in Mice
}

\author{
Nitin Govindrao Dumore ${ }^{1,2^{*}}$, Milind Janrao Umekar ${ }^{1}$, Brijesh Gulabrao Taksande ${ }^{1}$, Manish Manohar Aglawe ${ }^{1}$, \\ Nandkishor Ramdasji Kotagale ${ }^{3}$
}

\section{Nitin Govindrao Du- more ${ }^{1,2 *}$, Milind Janrao Umekar ${ }^{1}$, Brijesh Gula- braoTaksande', Manish Manohar Aglawe ${ }^{1}$, Nandk- ishor Ramdasji Kotagale ${ }^{3}$}

\section{'Division of Neuroscience, Department of Pharmacology, Smt.Kishoritai Bhoyar College of Pharmacy Kamptee, Nagpur 441002 Maharashtra, INDIA. \\ ${ }^{2}$ Dadasaheb Balpande College of Phar- macy, Besa, Nagpur,440037 Maharash- tra, INDIA. \\ ${ }^{3}$ Department of Pharmacognosy, Gov- ernment College of Pharmacy, Amara- vati, 444601, Maharashtra, INDIA. \\ Correspondence \\ Mr. Nitin Govindrao Dumore \\ Department of Pharmacology, Smt. Kishoritai Bhoyar, College of Pharmacy, New Kamptee, Nagpur (M.S.), 441 002, Maharashtra, INDIA. \\ Phone no : +91-8888406985 \\ E-mail: nitingdumore@gmail.com \\ History \\ - Submission Date: 10-03-2018; \\ - Review completed: 27-04-2018; \\ - Accepted Date: 29-11-2018}

DOI : 10.5530/pj.2019.1.8

Article Available online

http://www.phcogj.com/v11/i1

\section{Copyright}

(C) 2019 Phcog.Net. This is an openaccess article distributed under the terms of the Creative Commons Attribution 4.0 International license.

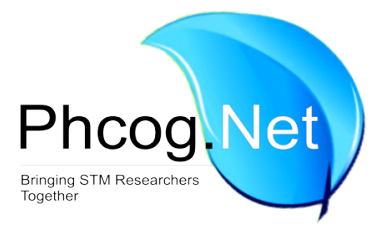

\begin{abstract}
Background: Herbal medicines can be novel treatment strategies for management of nicotine addiction. Withania somnifera (Ashwagandha) is an Indian medicinal plant of great medicinal value; used in many clinically proven conditions. Objective: In present study we aimed at investigating the effect of withania somnifera extract (WSE) on preventing nicotine mediated effects attributed for the development of addiction. Materials and Methods: Mice were treated with nicotine and/or WSE and subjected to nicotine induced conditioned place preference (CPP) in male albino mice was checked. Results: Application of two-way ANOVA showed that with preconditioning and post-conditioning values as a within-subjects (column) factor and treatment as an independent between subject (row) factor. Two-way ANOVA revealed significant effect of treatment $[F(3,40)=4.119, p<0.05]$, time $[F(1,40)=23.76, p<0.001]$ and interaction $[F(3,40)=5.244, p<0.01]$ on Intra-peritoneal (ip) administration of nicotine $(1 \mathrm{mg} / \mathrm{kg})$. WSE did not produce any changes in the preference to drug-paired compartment. Factors like treatment $[F(3,40)=0.656, p>0.05]$, time $[F(1,40)=7.383, p<0.01]$ and interaction $n_{\text {tratment } x \text { time }}[F(3,40)=$ $0.5748, p>0.05]$ showed insignificant effects. Withania somnifera $(50,100,200 \mathrm{mg} / \mathrm{kg} \mathrm{ip})$ coadministered with nicotine during the 6 days conditioning sessions completely abolished the acquisition of nicotine-induced CPP in mice. Conclusion: Above data indicate that Withania somnifera attenuate nicotine induced CPP. Hence it has potential as an anti-addictive therapy. Key words: Condition place preference, Nicotine, Withania somnifera.
\end{abstract}

\section{INTRODUCTION}

Quantification of the rewarding effect of addictive drug has widely assessed by employing self-administration or CPP test. ${ }^{1}$ CPP occurs when the animals prefer one context more than others. This preference is known to associate with rewarding feeling paired previously with pleasing events. ${ }^{2}$ Thus, CPP paradigm is widely used to explore the reinforcing effects of natural and pharmacological stimuli, including drugs of addiction. To understand and treat dependence disorders, researchers have utilized place conditioning to develop appropriate models of addiction. ${ }^{3}$ Place conditioning is broadly defined as a pairing between an unconditioned stimulus (US) and a conditioned stimulus (CS) where the US is the administration of the drug or other reward to the model organism and the CS is the distinct environment in which the organism is placed after administration of the drug or reward. ${ }^{4} \mathrm{CPP}$ is based on a motivational aspect of the investigated drug and can be defined as an inclination for the model organism to choose the location paired with the drug.

Early CPP studies with nicotine found discrepant findings between laboratories, which included no effect, CPP, or CPA. In an attempt to clarify these dis- crepancies, tested nicotine for CPP by first assessing the most and least preferred sides of a three-chamber shuttle box which is termed as biased or unbiased protocol. These discrepancies were associated with animals strains and dos, ${ }^{5}$ Nicotine showed CPP in the Lewis rats, but not in the Fischer-344. ${ }^{6}$ Systemic administration of nicotine has been shown to produce both CPP and CPA in rodents through stimulation of nicotinic acetylcholine receptors (nAChrs)..$^{7-8}$ Both CPP and CPA are observed at low and high doses, respectively. Pretreatment of mice with WSE dose-dependently prevented CPP acquisition - that is learning the association between affective interoceptive properties of morphine and environmental stimuli - an effect that might be attributed to a number of factors, including opposite motivational properties of WSE and WSE antagonism at $\mathrm{U}$-opioid receptors. In agreement with a number of CPP studies with plant extracts, ${ }^{9-10}$ WSE also blocked morphine-elicited CPP expression via involvement of $\mathrm{GABA}_{b}$ receptors. ${ }^{11}$ The results of the study demonstrated, in agreement with other study, that ethanol, under appropriate experimental conditions, elicited both CPP and CPA and that the standardized root extract of Withania
Cite this article: Dumore NG, Umekar MJ, Taksande BG, Aglawe MM, Nandkishor RR. Withania somnifera Attenuates Nicotine Induced Conditioned Place Preference in Mice. Pharmacog J. 2019;11(1):43-7. 
somnifera was able to impair both acquisition and expression of ethanolelicited CPP and CPA. ${ }^{12-13}$

In the present study we hypothesized that modulation of stress by herbal interventions may modulate the rewarding potential of nicotine. CPP was employed to test the rewarding effect of nicotine in Swiss-albino mice. Effect of WSE was studied on nicotine-induced CPP.

\section{MATERIALS AND METHODS}

\section{Animals}

Swiss albino mice (22-30 g) were used in the study. Animals were purchased from the National Institute of Nutrition, Hyderabad, India and kept in the animal house facility of SKB College of Pharmacy, Kamptee, Nagpur. Animals were housed in group of 10 mice per cage in acrylic cages $(24 \times 17 \times 12 \mathrm{~cm})$ under a constant room temperature $\left(25 \pm 2^{\circ} \mathrm{C}\right)$, relative humidity $(50 \pm 5 \%)$, and maintained under a controlled 12:12-h light-dark cycle (lights on at 07:00 h). Rodent chow food pellets and tap water were offered to the animals ad libitum. All the experimental procedures were approved and carried out under strict compliance with Institutional Animal Ethics Committee, constituted for the purpose of control and supervision of experimental animals by the Ministry of Environment and Forests, Government of India, New Delhi, India (853/ $\mathrm{PO} / \mathrm{Re} / \mathrm{S} / 04 / \mathrm{CPCSEA})$. Experiments were performed during the light cycle between 09:00 to 17:00-h to avoid circadian variations. Each experimental group had a separate set of animals and the care was taken to ensure that animals used for one experiment were not employed elsewhere. Animals were handled 5 days prior to actual starting of experiment and brought to experimental room at least $1 \mathrm{~h}$ before the test to minimize the non-specific stress induced behavioral alteration, if any.

Drugs: Nicotine hydrogen Tartarate, Withania somnifera extract. WSE and Nicotine were administered by ip.route in saline. The doses of nicotine and Withania somnifera extract were selected based on preliminary work carried out in our laboratory and available literature.

\section{Conditioned place preference: Apparatus}

The apparatus consisted of two rectangular Plexiglas boxes ( $48 \mathrm{~L} \mathrm{x} 20 \mathrm{~W}$ $\mathrm{x} 30 \mathrm{H} \mathrm{cm}$ ) separated by a guillotine door. The apparatus was placed in a soundproof room with constant light of 50 lux provided by a $5 \mathrm{~W}$ LED bulb placed above center of the apparatus. In one compartment inner wall was vertically striped black and white and with smooth white floor (A). In contrast, another compartment has horizontal black and gray striped walls and fine grid floor (B). The spontaneous preference was randomly distributed between compartments (49.19\% A and 50.81\% B).

\section{Experimental design}

\section{Acquisition of CPP}

$\mathrm{CPP}$ is three phase animal paradigm. We adapted the protocol from previously reported research articles. ${ }^{11,13}$ During the first phase (Day 1, Pre-conditioning), the guillotine door was kept raised and each mouse was placed randomly in one or the other compartment and allow to explore both compartment freely for $15 \mathrm{~min}$ ( $900 \mathrm{~s}$ ). The time spent in one compartment was recorded and taken as an indication of spontaneous (unconditioned) preference.

During the second phase (Days 2-6, Conditioning), mice were administered with saline or nicotine, WSE, per se or in combination. Immediately after nicotine administration mice were placed for $15 \mathrm{~min}$ to a given compartment and returned to their home cage. Four hours later, mice were given same treatment regimen except nicotine was replaced by saline and mice were immediately placed in the compartment opposite to that of the morning exposure. Thus one compartment represents saline, while other is paired with nicotine. We selected the interval of four hours between two sessions based on pharmacokinetic data available on WSE. This is in order to avoid any possible carry-over effect of the morning conditioning session to that of the afternoon.

Third phase of CPP paradigm is post-conditioning phase. During this phase (Day 7), the guillotine door between the two compartment was kept raised and mouse were place in one compartment. The time spent by each mouse in the nicotine-paired compartment during 15 min session was recorded. Identical experimental conditions were maintained during pre-conditioning and post-conditioning test. Pre- and post-conditioning test recordings were done by observers blind to the pharmacological treatments.

\section{Experimental protocol}

\section{Dose dependent effect of nicotine, WSE on place preference behavior in} mice

Animal from different groups were treated with saline or increasing doses of nicotine $(0.25,0.5$ and $1 \mathrm{mg} / \mathrm{kg}$, subcutaneous), WSE (50, 100 and $200 \mathrm{mg} / \mathrm{kg}$, ip), withanolide A, withanolide B and withaferin A (5, 10 and $20 \mathrm{mg} / \mathrm{kg}$, intraperitoneal). In the morning, mice were treated daily (Days 2 to 6) with nicotine, WSE, withanolide A, withanolide B or withaferine A and placed in drug-paired compartment for $15 \mathrm{~min}$. On the other hand, in the afternoon session, mice were treated with saline and placed in drug-paired compartment for $15 \mathrm{~min}$. On day 7, mice were exposed to apparatus without administering any drug and time spent in drug-paired compartment was measured.

\section{Effect of pretreatment of WSE nicotine-induced place preference behavior in mice}

In combination studies, we were aimed to investigate the effect of pretreatment of WSE on nicotine-induced place preference behavior in mice. In the morning session of days 2-6 (Conditioning), animals from different groups were first injected with WSE followed by nicotine 30 min later. Immediately after nicotine injection mice were placed in nicotine paired compartment $(\mathrm{A})$. In the afternoon session, mice received saline instead of WSE and nicotine injection. Mice were again placed in saline paired compartment (B). On day 7 (Post-conditioning), none of the groups received drug treatments and mice were placed in any one of the two compartment. Guillotine door was opened and time spend by mice in nicotine-paired compartment was measured during $15 \mathrm{~min}$ session.

\section{Statistical analysis}

Effect of nicotine on conditioning on acquisition of nicotine-elicited $\mathrm{CPP}$ and effect of pretreatment on nicotine elicited CPP was analyzed by two-way ANOVA with pre-conditioning and post-conditioning values as a within-subjects (column) factor and treatment as an independent between subject (row) factors. Bonferroni's multiple comparison test was employed for post-hoc comparison. $p<0.05$ was considered as statistically significant.

\section{RESULTS}

\section{Dose dependent effect of nicotine on CPP in mice}

Figure 1 shows the dose dependent effect of nicotine $(0.25,0.5$ and 1 $\mathrm{mg} / \mathrm{kg}$ ) on the CPP behavior in mice. To determine the effect of nicotine on conditioning on acquisition of nicotine-elicited CPP, data were analyzed by two-way ANOVA with pre-conditioning and post-conditioning values as a within-subjects (column) factor and treatment as an independent between subject (row) factor. Two-way ANOVA revealed significant effect of treatment $[\mathrm{F}(3,40)=4.119, \mathrm{p}<0.05]$, time $[\mathrm{F}(1,40)=23.76$, $\mathrm{p}<0.001]$ and interaction ${ }_{\text {treatment } x \text { time }}[\mathrm{F}(3,40)=5.244, p<0.01]$. Bonferroni's multiple comparison post-hoc analysis showed that mice receiving 
nicotine preferred drug-paired compartment during post-conditioning session $(0.5 \mathrm{mg} / \mathrm{kg}, p<0.01$ and $1 \mathrm{mg} / \mathrm{kg}, p<0.001)$ as compared to saline treated control animals. However, lower dose of nicotine $(0.25 \mathrm{mg} / \mathrm{kg})$ was found to be ineffective in exhibiting side preference. Side preference was not significantly different during preconditioning in any groups in study.

\section{Dose dependent effect of WSE on CPP in mice}

Figure 2 shows the dose dependent effect of WSE (50, 100 and $200 \mathrm{mg} /$ $\mathrm{kg}$, ip) on the CPP behavior in mice. On days 2-6, while WSE was given 6 in the morning session and saline was administered in the evening. At both sessions mice were kept in respective WSE- or saline-paired compartment for $15 \mathrm{~min}$. Two-way ANOVA with pre-conditioning and post-conditioning values as a within-subjects (column) factor and treatment as an independent between subject (row) factor was employed for checking the significant difference. WSE did not produce any changes in the preference to drug-paired compartment. Factors like treatment $[\mathrm{F}(3,40)=0.656, \mathrm{p}>0.05]$, time $[\mathrm{F}(1,40)=7.383, p<0.01]$ and interaction treatment $x$ time $[F(3,40)=0.5748, p>0.05]$ showed insignificant effects. Bonferroni's multiple comparison post-hoc analysis also showed no difference in the time spent in drug paired compartment during post-conditioning session by WSE treatment as compared to saline treated control animals. During pre-conditioning side preference was not significantly different any groups in study.

\section{Effect of pretreatment of WSE on nicotine-induced CPP in mice}

Figure 3 shows the effect of pretreatment with WSE (50, 100 and $200 \mathrm{mg}$ / $\mathrm{kg}$, ip) $30 \mathrm{~min}$ before the administration of nicotine $(1 \mathrm{mg} / \mathrm{kg})$ and exposure to the assigned compartment for $15 \mathrm{~min}$. Pre-conditioning preference times did not differ significantly between experimental groups. Application of two-way ANOVA suggested that pretreatment with WSE with nicotine produced statistically significant prevention of nicotine preference behavior in mice. Effect was significant in factors like treatment $[\mathrm{F}(4,50)=3.209, \mathrm{p}<0.05]$, time $[\mathrm{F}(1,50)=25.25, p<0.001]$ and interaction $_{\text {treatment } x \text { time }}[F(4,50)=3.785, p<0.01]$. Post-hoc Bonferroni's multiple comparison test showed that nicotine $(1 \mathrm{mg} / \mathrm{kg})$ treated mice spent more

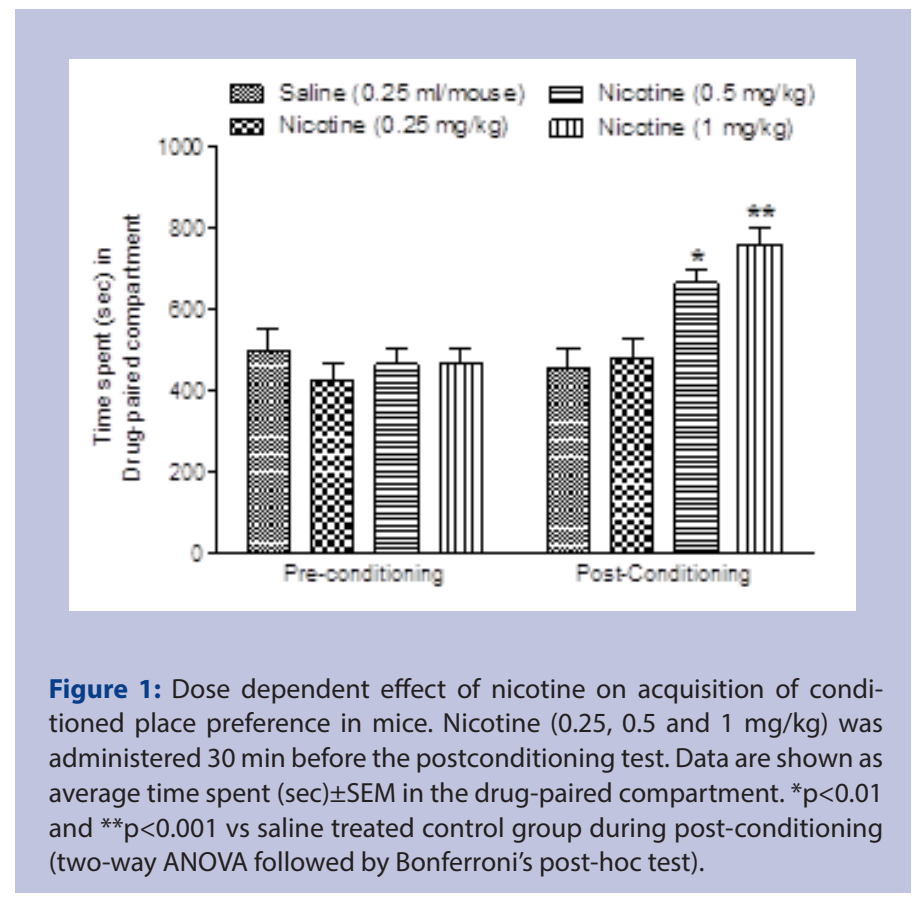

time in drug-paired compartment during post-conditioning phase as compared to those of saline control group $(p<0.01)$. Pretreatment with WSE $(50 \mathrm{mg} / \mathrm{kg}$ ) did not reverse nicotine preference during post-conditioning phase and these mice spent comparable time in nicotine-paired compartment as that of nicotine per se treatment group $(p>0.05)$. Time spent in nicotine-paired compartment was reduced by pretreatment with higher dose of WSE (100 and $200 \mathrm{mg} / \mathrm{kg}$ ) as compared to per se nicotine group ( $p<0.01$ and $p<0.001$, respectively).

\section{DISCUSSION}

The results of the present study demonstrate that the administration of WSE prevented acquisition of nicotine-elicited CPP in mice. Nicotine is well known substance of abuse present in tobacco. Number of studies demonstrated the rewarding and reinforcement activities of nicotine in different animal models such self administration and CPP. In agreement with 13 that nicotine, under appropriate experimental conditions, elicited CPP. CPP was developed to assess the rewarding potential of psychoactive substances in animals. In a typical CPP experiment, a stimulus of interest is conditioned to distinct environmental cues. The animal demonstrates a preference for the conditioned environment over the environment conditioned to a non-rewarding (placebo) stimulus if the stimulus is rewarding. It is readily adaptable to mice and does not require surgery or extensive training as that necessary for self-administration paradigms. We also noticed that nicotine produced CPP in mice in dose dependent manner. The nicotine treated animals spent significantly more time in the drug-paired compartment versus the vehiclepaired compartment. This indicated the rewarding potential of nicotine which may be responsible for the addiction liabilities of agent. Nicotine produced behavioral effects in mice with very narrow dose range. While lower dose may not produce any rewarding effect, higher dose may lead to seizure. In addition, prediction of rewarding activity, dose used in the study should not affect the locomotor behavior in animals. Thus it was very critical to select the dose of nicotine. Previously, we observed that $1 \mathrm{mg} / \mathrm{kg}$ of nicotine produced CPP in mice. ${ }^{14}$ Our results confirmed the rewarding potential of nicotine in CPP.

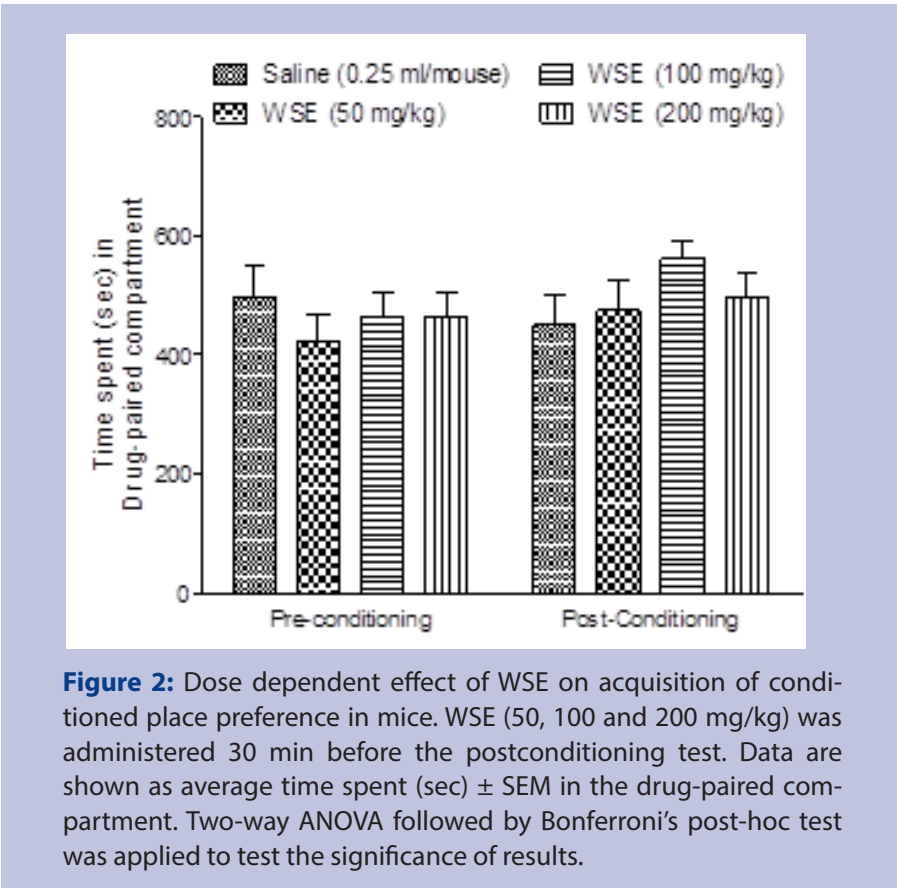




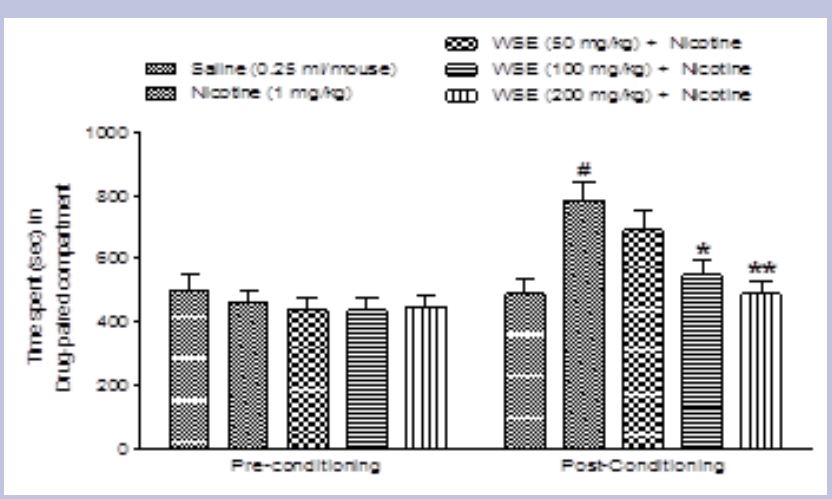

Figure 3: Effect of pretreatment with WSE on nicotine-induced conditioned place preference in mice. Mice were treated with saline, nicotine (1 $\mathrm{mg} / \mathrm{kg}$ ), or combination of WSE $(50,100$ and $200 \mathrm{mg} / \mathrm{kg}$ ) + nicotine. WSE was administered $30 \mathrm{~min}$ before each nicotine administration and mice were placed in nicotine paired compartment for $15 \mathrm{~min}$. Data are shown as average time spent (sec) \pm SEM in the drug-paired compartment. ${ }^{*} p<0.01$ and ${ }^{* *} p<0.001$ vs nicotine group (post-conditioning). $\# p<0.01$ vs saline group (post-conditioning).

Also, in our earlier findings, we found WSE enhance the nicotine induced locomotors sensitization and withdrawal induced anxiety in mice. In view of this, several studies have already established a role of Withania somnifera in attenuation of ethanol and morphine withdrawal syndrome. It also decreases cocaine and fentanyl self-administration and in habited morphine CPP. These findings supported by available literature. Several studies have demonstrated the antistress, adaptogenic and immunomodulatory potential of Withania somnifera. ${ }^{18-21}$ Indian ginseng like to Hypericum perforates and Panax ginseng shows 5-HT, GABA, acetylcholine and dopaminergic modulations, ${ }^{22-25}$ accounting for its CNS effects.

The main objective of the present study was to characterize further the ability of WSE to interfere with the rewarding properties of nicotine. Antagonistic potential of WSE in ethanol ${ }^{12}$ and morphine ${ }^{11}$ induced CPP was previously reported. We observed that WSE prevented the nicotineinduced acquisition of CPP. In addition, WSE dose-dependently prevented CPP acquisition. Our results indicate that, at least at the doses used in these experiments, WSE was devoid of motivational properties per se. Role of GABAa receptors was suggested in effect of WSE in ethanol-induced CPP. Some studies were aimed at finding the role of mu-opioid receptors in the action of WSE. However, WSE showed low binding affinity to mu-opioid receptors ${ }^{11}$ and elicit naloxone-like effect. Previously it was demonstrated that WSE affect preferentially events in the cortical and basal forebrain cholinergic signal transduction cascade. ${ }^{15}$ The drug-induced increase in cortical muscarinic acetylcholine receptor capacity may lead to pharmacological effects. In addition, in silico studies documented the agonistic activity of phytoconstituents of WSE to nicotinic cholinergic activity. ${ }^{16}$ Previously role of nicotinic cholinergic receptor (alpha4-beta2) is reported in nicotine-induced CPP behavior. ${ }^{17}$ This collectively suggests that WSE may be via acting on nicotinic cholinergic receptor mediate nicotine CPP.

Further biochemical and neurological investigations at molecular level to identify exact anti-addictive mechanism of WSE may be warranted.

In conclusion, all of the above results suggest that WSE was effective in reversing nicotine CPP. Although we did not perform any studies to dig out the exact mechanism of WSE, this effect might be attributed to action on one or more of a number of possible targets particularly nicotinic cholinergic receptors. In this regard, future investigations on the applica- tion of Withania somnifera, and other herbal remedies, in the scenario of prevention and treatment of distinct aspects of smoking may represent promising advances.

\section{CONFLICT OF INTEREST}

The authors declare no conflict of interest.

\section{ACKNOWLEDGEMENT}

The authors are gratefully acknowledging to animal house of the National Institute of Nutrition, Hyderabad, India for providing animals for the research work. As well authors would like to thank the Department of Pharmacology and administration of Smt. Kishoritai Bhoyar, College of Pharmacy, New Kamptee, Nagpur, Maharashtra for permission to study and providing necessary facility to carry out the research work.

\section{ABBREVIATIONS}

nAChRs: nicotinic acetylcholine receptors; WSE: Withania Somnifera extract; ip: intraperitoneal; CPP: Condition place preference.

\section{REFERENCES}

1. Carboni $E$, Acquas $E$, Leone P, Di Chiara G. 5 HT3 receptor antagonists block morphine-and nicotine-but not amphetamine-induced reward. Psychopharmacology (Berl). 1989;97:175-8.

2. Huston JP, Silva MA, Topic B, Müller CP. What's conditioned in conditioned place preference?. Trends Pharmacol Sci. 2013;34(3):162-6.

3. Carboni E, Vacca C. Conditioned place preference a simple method for investigating reinforcing properties in laboratory animals. Methods Mol Med. 2003;79:481-98.

4. Tzschentke TM. Measuring reward with the conditioned place preference paradigm: a comprehensive review of drug effects, recent progress and new issues. Prog Neurobiol. 1998;56:613-72.

5. Calcagnetti DJ, Schechter MD. Extinction of cocaine-induced place approach in rats: a validation of the "biased" conditioning procedure. Brain Res Bull. 1993;30:695-700

6. Philibin SD, Vann RE, Varvel SA, Covington HE, Rosecrans JA, James JR, et al. Differential behavioral responses to nicotine in Lewis and Fischer-344 rats. Pharmacol Biochem Behav. 2005;80:87-92.

7. Fudala PJ, Teoh KW, Iwamoto ET. Pharmacologic characterization of nicotine-induced conditioned place preference. Pharmacol Biochem Behav. 1985;22:23741.

8. Le Foll B, Goldberg SR. Nicotine induces conditioned place preferences over a large range of doses in rats. Psychopharmacology (Berl). (2005);178;481-92.

9. Sahraei H, Fatemi SM, Pashaei-Rad S, Faghih-Monzavi Z, Salimi SH, Kamalinegad M. Effects of Papaver rhoeas extract on the acquisition and expression of morphine-induced conditioned place preference in mice. J Ethnopharmacol. 2006;103:420-4.

10. Mattioli L, Titomanlio F, Perfumi M. Effects of a Rhodiola rosea L. extract on the acquisition, expression, extinction, and reinstatement of morphineinduced conditioned place preference in mice. Psychopharmacology (Berl). 2012;221:183-93

11. Ruiu S, Longoni $R$, Spina $L$, et al. Withania somnifera prevents acquisition and expression of morphine-elicited conditioned place preference. Behav Pharmacol. 2013;24:133-43.

12. Spina L, Longoni R, Rosas M. Withania somnifera Dunal (Indian ginseng) impairs acquisition and expression of ethanol-elicited conditioned place preference and conditioned place aversion. J Psychopharmacol. 2015;29:1191-9.

13. Cunningham $\mathrm{CL}$, Okorn DB, Howard CE. Interstimulus inter-val determines whether ethanol produces conditioned place prefer-ence or aversion in mice. Anim Learn Behav. 1997;25:31-42.

14. Nandkishor RKSW, Gajanan PS, Dadasaheb MK, Milind JU, Brijesh GT. Agmatine attenuates nicotine induced conditioned place preference in mice through modulation of neuropeptide $Y$ system. Behavioral Brain Research. 2014;262:118-24.

15. Schliebs R, Liebmann A, Bhattacharya SK, Kumar A, Ghosal S, Bigl V. Systemic administration of defined extracts from Withania somnifera (Indian Ginseng) and Shilajit differentially affects cholinergic but not glutamatergic and GABAergic markers in rat brain. Neurochem Int. 1997;30(2):181-90.

16. Remya C, Dileep KV, Variayr EJ, Sadasivan C. Silico guided identification of $n A C h R$ agonistsfrom Withania somnifera. Frontiers in Life Science. 2016;9(3):201-13.

17. Walters $C L$, Brown S, Changeux J-P, et al. The beta2 but not alpha7 subunit of the nicotinic acetylcholine receptor is required for nicotine-conditioned place preference in mice. Psychopharmacology. 2006;184:339-44. 
18. Archana R, Namasivayam A. Antistressor effect of Withania somnifera. J Ethnopharmacol. 1999;64(1):91-3.

19. Bhattacharya SK, Muruganandam AV. Adaptogenic activity of Withania somnifera: An experimental study using a rat model of chronic stress. Pharmacol Biochem Behav. 2003;75(3):547-55.

20. Dhuley JN. Effect of ashwagandha on lipid peroxidation in stress- induced animals. J Ethnopharmacol. 1998;60(2):173-8.

21. Ziauddin M, Phansalkar N, Patki P, Diwanay S, Patwardhan B. Studies on the immunomodulatory effects of Ashwagandha. J Ethnopharmacol. 1996;50(2):6976.

22. Mehta AK, Binkley P, Gandhi SS, Ticku MK. Pharmacological effects of Witha- nia somnifera root extract on GABA A receptor complex. Indian J Med Res 1991:94:312-5

23. Kulkarni SK, George B. Anticonvulsant Action of Withania somnifera (Aswaganda) Root Extract against Pentylenetetrazol- induced Kindling in Mice Phytotherapy. 1996;10(5):447-9.

24. Koob GF, Michel Le Moal. Neurobiological mechanisms for opponent motivational processes in addiction. Phil Trans R Soc. B. 2008;363(1507): 3113-23.

25. Tohda C, Kuboyama T, Komatsu K. Dendrite extension by methanol extract of Ashwagandha (roots of Withania somnifera) in SK-N-SH cells. Neuroreport. 2000;11(9):1981-5

\section{GRAPHICAL ABSTRACT}

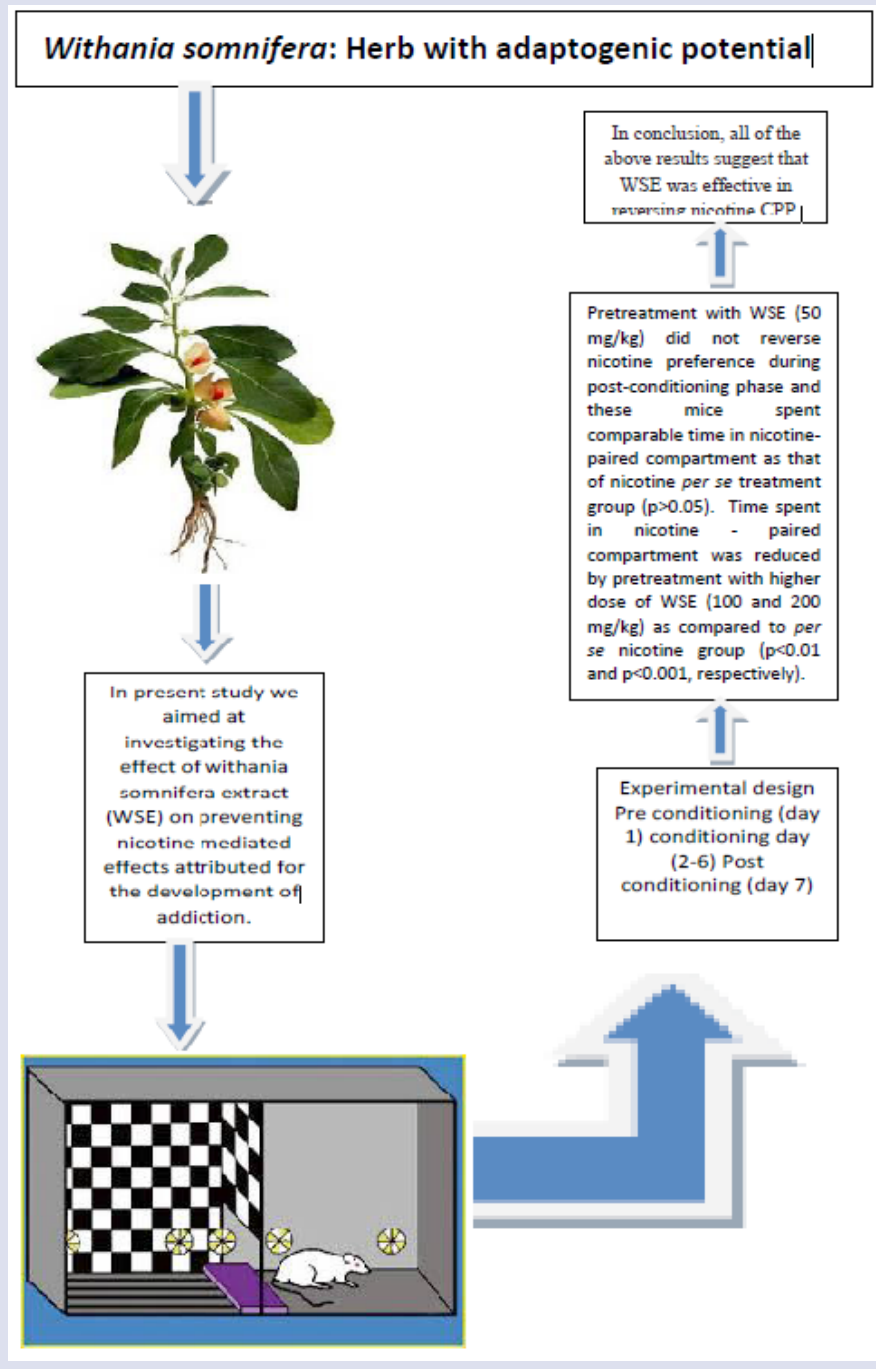

\section{SUMMARY}

- The main objective of the present study was to characterize the ability of WSE to interfere with the rewarding properties of nicotine. Antagonistic potential of WSE in ethanol and morphine induced CPP was previously reported. We observed that WSE prevented the nicotine-induced acquisition of CPP. In addition, WSE dose-dependently prevented CPP acquisition. all of the above results suggest that WSE was effective in reversing nicotine CPP. Although we did not perform any studies to dig out the exact mechanism of WSE, this effect might be attributed to action on one or more of a number of possible targets particularly nicotinic cholinergic receptors. In this regard, future investigations on the application of Withania somnifera, and other herbal remedies, in the scenario of prevention and treatment of distinct aspects of smoking may represent promising advances.

\section{ABOUT AUTHORS}

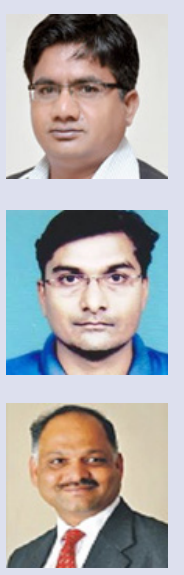

Dr. Nandkishor R. Kotagale: Presently working as Associate Professor at Department of Pharmacognosy, Government College of Pharmacy, Amaravati, 444601, Maharashtra, India.

Nitin Govindrao Dumore: Presently working as Ph.D. scholar at Division of Neuroscience, Department of Pharmacology, Smt. Kishoritai Bhoyar College of Pharmacy Kamptee, Nagpur 441002 Maharashtra, India.

Dr.Milind J.Umekar: Presently working as Principal and Professor at Smt. Kishoritai Bhoyar College of Pharmacy Kamptee, Nagpur 441002 Maharashtra, India.

Dr. Brijesh G. Taksande: Presently working as Associate Professor at Division of Neuroscience, Department of Pharmacology, Smt. Kishoritai Bhoyar College of Pharmacy Kamptee, Nagpur 441002 Maharashtra, India.

Manish M. Aglawe: Presently working as Asst. Professor at Division of Neuroscience, Department of Pharmacology, Smt. Kishoritai Bhoyar College of Pharmacy Kamptee, Nagpur 441002 Maharashtra, India.

Cite this article: Dumore NG, Umekar MJ, Taksande BG, Aglawe MM, Nandkishor RR. Withania somnifera Attenuates Nicotine Induced Conditioned Place Preference in Mice. Pharmacog J. 2019;11(1):43-7. 